\title{
Impulsive Breakdown of Mineral Oil and Natural and Synthetic Ester Liquids When Containing Varying Levels of Moisture
}

\author{
Chris Williamson, Graduate Student Member, IEEE, Igor Timoshkin, Senior Member, IEEE, Scott J. \\ MacGregor, Senior Member, IEEE, Mark P. Wilson, Member, IEEE , Martin J. Given, Senior \\ Member, IEEE, M. Sinclair, Member, IEEE, A. Jones, Senior Member, IEEE
}

\begin{abstract}
This paper reports and discusses the results of impulse breakdown study of different insulating liquids under highly divergent electric field conditions. Samples of a natural ester (Envirotemp FR3), a synthetic ester (MIDEL 7131) and a naphthenic mineral oil (Shell Diala S4 ZX) at different levels of relative humidity were exposed to $\mathrm{HV}$ impulses with a nominal $7 \mu \mathrm{s}$ rise time and $150 \mathrm{kV}$ peak voltage of both positive and negative polarity. A strong dependence of the breakdown voltage and time to breakdown of the investigated dielectric liquids was observed with respect to the polarity of the applied $\mathrm{HV}$ impulses. It was shown that the FR3 natural ester liquid has a higher dielectric strength when exposed to positive impulse than when under negative impulse stress. The opposite breakdown behaviour was observed for the synthetic ester MIDEL 7131 and the naphthenic oil Shell Diala S4 ZX which exhibited lower breakdown voltage under positive energisation as compared with the negative energisation. The breakdown voltage and pre-breakdown time obtained in the present tests of the naphthenic oil, Shell Diala S4 $\mathrm{ZX}$ lie between that of the ester liquids irrespective of impulse polarity. It has been established that no statistically significant variations exist in the breakdown parameters (breakdown voltage and time to breakdown) of the studied dielectric liquids as their relative humidity is increased under either impulse polarity. The obtained results will help in coordination of practical applications of low environmental impact dielectric fluids in power and pulsed power systems and components.
\end{abstract}

Index Terms-Dielectric breakdown, dielectric liquids, divergent electric field, ester liquids, impulse breakdown, oil insulation, relative humidity

\section{INTRODUCTION}

$\mathrm{I}^{\mathrm{n}}$ $n$ recent decades there has been a paradigm shift in the attitudes towards the environmental impact of industrial, commercial and domestic operations. Statutes [1] have placed a responsibility on industry to reduce the environmental impacts of its operations. This has resulted in the power and,

Chris Williamson, Igor V. Timoshkin, Scott J. MacGregor, Mark P. Wilson, and Martin J. Given are with the Department of Electronic and Electrical Engineering, University of Strathclyde, Glasgow G1 1XW, U.K. (e-mail: Chris.williamson@strath.ac.uk).

Mark Sinclair and Aled Jones are with AWE PLC, Aldermaston, U.K latterly, the pulsed power industry searching for methods to mitigate environmental impact. One such area is the use of naphthenic based insulating fluids within large electrical machines; such as power transformers and pulsed power systems. The power industry has already taken steps to mitigate possible environmental impacts resulting from the use of nonbiodegradable liquid dielectrics. Currently, natural and synthetic ester fluids which have high biodegradability and low toxicity are used instead of conventional naphthenic mineral oil in some distribution and power transformers, $[2,3,4]$. These ester insulating fluids have been shown to offer a comparable electrical and thermal performance to conventional mineral oils for most insulating applications in the power industry, $[5,6]$. Studies $[11,12]$ also demonstrated a comparable AC breakdown performance for ester fluids and conventional naphthenic liquids. It is known that such AC breakdown tests can be used to identify only the influence of contaminants such as water and particulates on the breakdown voltage, but not the intrinsic properties of the fluid, $[13,14]$.

Almost universally a reduction is observed in the $\mathrm{AC}$ breakdown voltage of the conventional naphthenic insulation oils, seen to manifest at $\sim 20 \%$ relative humidity. The reduction in breakdown strength increases with the moisture content.

It was shown that the $\mathrm{AC}$ breakdown strength of ester liquids is less sensitive to their water content, which can seriously impact the breakdown strength of naphthenic mineral oils, [8, 9]. In [8] it is shown that moisture content has a larger effect on the AC breakdown strength of mineral oil (measured at power frequency) as compared with both natural and synthetic esters. When the relative humidity was increased from $\sim 10 \%$ to $\sim 30 \%$, the naphthenic oil experienced a $\sim 30 \%$ reduction in $\mathrm{AC}$ breakdown voltage, whereas the breakdown voltage of the two ester fluids did not show statistically significant changes with a similar increase in their relative humidity.

In [9], it was found that the AC breakdown voltage of a mineral oil at $\sim 35 \%$ RH dropped to $\sim 65 \%$ of that of the dry oil. Paper [10] provides the AC breakdown voltage for conventional mineral oil and Envirotemp FR3 natural ester fluid as a function of their absolute water content (as compared with dry liquids): the breakdown voltage of the mineral oil was reduced by $\sim 80 \%$ at $100 \mathrm{ppm}$ moisture content, but the 
breakdown voltage of the natural ester reduces by only $\sim 40 \%$ at $\sim 530$ ppm moisture content.

Additional performance benefits that ester fluids offer as compared to traditional naphthenic oils include an improved safety profile due to their higher flash and fire points [7].

The principle application of ester fluids to date has been as the liquid insulating medium within power and distribution transformers, $[2,3]$, where these liquids are stressed with $\mathrm{AC}$ voltages at power frequency. Such applications drove extensive experimentation to characterise the breakdown behaviour of ester liquids under conventional $(50 / 60 \mathrm{~Hz}) \mathrm{AC}$ stresses. However, recent developments in HVDC power transmission technology, and requirements to use environmentally friendly liquids in pulsed power machines, dictate that detailed information on the breakdown behaviour of natural and synthetic esters is required, not only in the case of $\mathrm{AC}$ energisation, but also when stressed with HVDC or HV impulses, [15, 16].

For example, in order to ascertain more complete information on the characteristic breakdown behaviours of a dielectric liquid, impulse breakdown experimentation is also required, $[17,18]$. However, the results obtained for impulse experimentation are heavily influenced by electrode geometry, inter-electrode spacing, applied voltage level and rate of rise of voltage, so direct comparison between published results is not always possible.

In [19] it was discussed, and experimentally demonstrated, how such factors can influence the dielectric behaviour of insulating liquid when under impulse stress. Breakdown characteristics of Envirotemp FR3 natural ester, MIDEL 7131 synthetic ester and a naphthenic mineral oil, Gemini X, were obtained using four differing impulse test methodologies: the "rising voltage" test with one and three breakdown events, [17]; "up and down" test, [20]; and "multi-level" test, [21]. The largest different between obtained breakdown voltages, $V_{b k}$, of the tested fluids was registered using the "rising voltage" method with three breakdown events: $\sim 19 \%$ and $\sim 20 \%$ reduction in $V_{b k}$ for MIDEL 7131 and Envirotemp FR3 liquids as compared with mineral oil, Gemini X. The minimum difference in $V_{b k}$ values was obtained using the "up and down" method; $\sim 4 \%$ and $\sim 10 \%$ reduction for the MIDEL 7131 and Envirotemp FR3 liquids respectively, as compared with Gemini X oil.

The authors of [22] did not find a statistically significant difference in the breakdown voltages of Envirotemp FR3 and MIDEL 7131 ester liquids under lighting impulse stress for both polarities. Moreover, for positive energisation [22] reports the same breakdown voltage for all three tested liquids; the ester fluids and the mineral oil. However, in the case of the negative lighting impulses, the breakdown voltage of both esters is lower than that of the mineral oil by $\sim 26 \%$.

It is reported that the difference in the impulsive breakdown performance of natural ester liquid and mineral oil depends on the field utilisation factor, $\eta$ which provides a measure of field non-uniformity in the gap being the ratio of the average field in the gap to the maximum field at the point electrode. In [39] breakdown voltage of Envirotemp FR3 natural ester and Nytro
Lyra X mineral oil are reported as a function of $\eta$. The breakdown tests described in [39] were conducted in accordance with ASTM D3300 standard using negative lighting impulses. It was shown that for $\eta$ in the range of $\sim(0.08-0.4)$, there is no statistically significant difference in the breakdown voltages of FR3 ester liquid and Nytro Lyra X mineral oil. However, for $\eta \sim(0.04-0.07)$ and smaller, the breakdown voltage of the ester liquid is significantly lower than that of the mineral oil, for example for $\eta \sim 0.02$ this difference in the breakdown voltages is $\sim 43 \%$.

Breakdown voltage of insulating liquids is reported as a function of electrode spacing in [23] under positive and negative polarity of lightning impulses. For positive impulses no discernible difference exists between $\mathrm{V}_{50 \%}$ breakdown voltages (breakdown voltage for $50 \%$ breakdown probability) of MIDEL 7131, Envirotemp FR3 and Gemini X insulating liquids at $25 \mathrm{~mm}$ electrode spacing. However, for longer distances $\mathrm{V}_{50 \%}$ of the mineral oil is greater than that of the esters; for $75 \mathrm{~mm}$ gap distance this difference is $\sim 33 \%$ (both esters at this distance have the same $\mathrm{V}_{50 \%}$ ). In the case of negative energisation [22] reported similar values of $\mathrm{V}_{50 \%}$ for for both esters but, akin to positive energisation, the mineral oil demonstrated $\sim 31 \%$ greater $\mathrm{V}_{50 \%}$ than that registered to the ester fluids.

Similar functional dependency of $\mathrm{V}_{50 \%}$ for a rape-seed oil and traditional unidentified mineral oil is reported in [26] where negative $\mathrm{V}_{50 \%}$ of mineral oil is $\sim 55 \%$ higher than that for natural ester when the inter-electrode gap is $20 \mathrm{~mm}$; with this difference seen to reduce to $\sim 10 \%$ at $10 \mathrm{~mm}$ spacing.

As discussed above, moisture content is shown to exert influence over the AC breakdown properties of an insulating fluid, [8, 9, 37, 38]. However, these works do not consider how the divergence of the applied electric field may affect the AC breakdown voltage; with most tests conducted using either sphere-sphere, $[8,37]$, or electrodes profiled according to the ASTM D1816 standard, [38]. Consequently, differences in the breakdown behaviour arising from increased field nonuniformity (field enhancement in the vicinity of the sharp HV electrode), will not be interpretable. Therefore, it is important to conduct an experimental study which will facilitate categorisation of the behaviours of dielectric fluids when in an elevated state of relative humidity, and exposed to highly divergent electric field conditions.

Neither the lightning impulse testing method in the ASTM D3300 standard, nor other impulsive breakdown test methods (as discussed in [19]), require the provision of data on time to breakdown. However, information on time to breakdown is of great importance to pulsed power operators; given that the insulating medium within pulsed power systems could be highly overstressed for short time intervals. Therefore, data on the breakdown voltage and the time to breakdown in an overstressed impulsive regime is critical for selection and coordination of liquid dielectrics in pulsed power components and systems.

The work presented starts to address this gap in knowledge by investigating the impulsive breakdown voltage and the time to breakdown of two ester liquids and a mineral oil in three 
discrete states of relative moisture content. These states were: the level of relative humidity as provided by their manufactures; the ambient relative humidity of the laboratory environment and an elevated relative humidity $\sim 70 \%$.

Samples of natural ester Envirotemp FR3 (Cargill Ltd, USA), synthetic ester MIDEL 7131 (M\&I Materials Ltd, UK) and mineral oil Diala S4 ZX (Shell Ltd) in each of the three states of relative humidity were exposed to high voltage impulses with a nominal rise time of $\sim 7 \mu$ s and fall time to the half of the peak voltage of $\sim 170 \mu$ s of both positive and negative polarity. The breakdown tests were conducted in a needle-sphere electrode configuration. The breakdown voltage, $V_{b k}$, and time to breakdown, $t_{b k}$, were obtained in an overstressed regime, i.e. each applied HV impulse resulted in breakdown of the insulating liquid. All breakdown events were registered on the rising slope or around the peak of each applied HV impulse. Both $V_{b k}$ and $t_{b k}$ were measured for all three liquids, in order to compare the performance of the ester fluids with that of conventional mineral oil in an impulsive overstressed regime, in a highly divergent electric field with $\eta \sim 0.01$

\section{MATERIALS AND METHODS}

\section{A. Liquids Selected for Investigation}

The key nominal characteristics of the liquids selected for this study obtained from $[43,44,45]$ are summarised in Table 1.

As can be seen from Table 1, both ester fluids demonstrate the increased ability to accommodate moisture due to the much higher water saturation limit of these fluids. This attribute may offer potential improvements in operational performance of ester fluids in comparison to naphthenic oils in conditions with elevated humidity given the sensitivity of breakdown voltages of mineral oils to their relative humidity, $[8,9]$.

TABLE I. Key parameters of examined dielectric fluids (adapted from $[43,44,45]$ )

\begin{tabular}{lccc}
\hline \hline & $\begin{array}{c}\text { Shell Diala } \\
\text { S4 ZX }\end{array}$ & MIDEL 7131 & $\begin{array}{c}\text { Enivrotemp } \\
\text { FR3 }\end{array}$ \\
\hline $\begin{array}{l}\text { Composition } \\
\text { hydro- } \\
\text { carbons }\end{array}$ & $\begin{array}{c}\text { Pentaerythritol } \\
\text { tetra ester }\end{array}$ & $\begin{array}{c}\text { Plant based } \\
\text { ester }\end{array}$ \\
$\begin{array}{l}\text { Degree of } \\
\text { biodegradability }\end{array}$ & Non & Highly & Highly \\
$\begin{array}{l}\text { Oxidisation } \\
\text { Water Saturation }\end{array}$ & $\begin{array}{c}\text { Mildly } \\
\text { susceptible }\end{array}$ & Non-susceptible & Susceptible \\
$\begin{array}{l}\text { Flash Point } \\
\text { Permittivity }\end{array}$ & $191^{\circ} \mathrm{C}$ & $2600 \mathrm{ppm}$ & $1100 \mathrm{ppm}$ \\
$\begin{array}{l}\text { Dielectric } \\
\text { strength (AC } \\
\text { power frequency) }\end{array}$ & 2.2 & $260^{\circ} \mathrm{C}$ & $316-330^{\circ} \mathrm{C}$ \\
\hline \hline
\end{tabular}

The breakdown behaviour of these liquids was examined under three different levels of relative humidity. The 'As Received' condition (lowest \%RH) relates to liquid samples taken from newly opened containers in the condition as provided by the manufacturer. In the case of the 'Ambient RH' condition the liquids were exposed to the ambient laboratory conditions so the relative humidity of liquid reached an equilibrium with RH of ambient atmospheric air. Liquids in the 'Elevated RH' were kept within a sealed chamber containing a water mist generated by an ultrasonic humidifier until they reached equilibrium.

TABLE II. Moisture levels used in the tests

\begin{tabular}{lllllll} 
Liquid & \multicolumn{2}{c}{ As Received } & \multicolumn{2}{c}{ Ambient RH } & \multicolumn{2}{c}{ Elevated RH } \\
& RH & ppm & RH & ppm & RH & ppm \\
\hline $\begin{array}{l}\text { Shell } \\
\text { Diala }\end{array}$ & $21 \%$ & $\sim 15$ & $35 \%$ & $\sim 25$ & $70 \%$ & $\sim 49$ \\
Midel & $13 \%$ & $\sim 325$ & $34 \%$ & $\sim 884$ & $72 \%$ & $\sim 1872$ \\
$\mathbf{7 1 3 1}$ & & & & & & \\
FR3 & $9 \%$ & $\sim 99$ & $34 \%$ & $\sim 374$ & $73 \%$ & $\sim 803$ \\
\hline \hline
\end{tabular}

The relative humidity of the liquid samples was measured using a humidity and temperature probe, Omniport 20. Using the reference values of water saturation given in Table 1, the absolute moisture content values were obtained for all tested liquids for the three RH states. Both, measured RH values and calculated moisture content values for the tested liquids are given in Table 2.

\section{B. High Voltage Test Bed}

The voltage impulse used for the breakdown measurements was generated with a Marx-type pulsed power generator. A high voltage direct current power supply (Glassman, USA) was used to charge a five-stage air insulated inverting Marx generator through a series configured protection resistor stack. A charging DC voltage of $30 \mathrm{kV}$ was used in all tests, allowing production of $\mathrm{HV}$ impulses with a peak nominal amplitude of $150 \mathrm{kV}$. Impulses of both polarities were used in the present work. Triggering of the impulse generator was achieved through a pneumatic process in which closing of the spark switches occurred as a result of a reducing the pressure within the spark column.

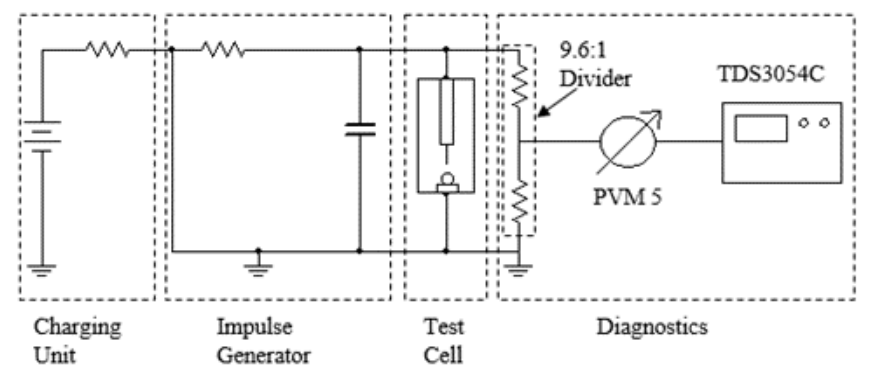

Fig. 1. Experimental setup. The Marx generator is represented as a lumped RC circuit.

The output terminals of the impulse generator were connected to wave shaping resistors to achieve $\mathrm{a} \sim 7 \mu$ s nominal rise time and a $\sim 170 \mu$ s nominal fall time. To measure the HV wave-forms during the breakdown tests a HV divider was 
connected in parallel with the test cell. This custom built divider, a $\mathrm{CuSO}_{4}$ water solution filled column, was coupled to a commercial HV probe, NorthStar PVM5, with a nominal bandwidth of $80 \mathrm{MHz}$. All experimental voltage signals were captured and recorded using a Textronix TDS3054C digitising oscilloscope ( $500 \mathrm{MHz}, 5 \mathrm{Gs} / \mathrm{s})$. The schematic diagram of the $\mathrm{HV}$ test system is given in Figure 1.

The test cell used within all the breakdown tests was manufactured from glass reinforced Nylon and has a total volume of $\sim 150 \mathrm{ml}$. A gramophone needle with a nominal tip radius of $\sim 35 \mu \mathrm{m}$ was used as the $\mathrm{HV}$ electrode, and a $12.7 \mathrm{~mm}$ diameter spherical mild steel ball bearing was used as a ground electrode. A fixed $0.8 \mathrm{~cm}$ inter-electrode gap distance was used in the tests.

The Laplacian electric field distribution in this needle-sphere electrode configuration was modelled using QuickField electrostatic field solver software. Figure 2 shows the magnitude of the electric field along a virtual straight line between the tip of the needle electrode and the pole of the grounded sphere, the applied voltage in this example is $V_{a p p}=150 \mathrm{kV}$. The Laplacian field magnitude reduces from its maximum value, $E_{\max }$, at the tip of the needle $(d=0 \mathrm{~cm})$, to its minimum value at $\sim 0.5 \mathrm{~cm}$ away from the $\mathrm{HV}$ needle, and then increases slightly at the surface of the grounded spherical electrode, $(d=0.8 \mathrm{~cm})$.

$E_{\max }$ governs the breakdown initiation processes at the tip of the HV electrode. It should be emphasised that the maximum field at the needle electrode strongly depends upon the tip radius; however, this radius is known only approximately, and the tip of the needle electrode is subjected to erosion by spark discharges during the breakdown tests. Also, this electrostatic field modelling does not take into account any potential space charge effects due to the finite electrical conductivity of the insulating liquid(s), which may result in a noticeable reduction of $E_{\max }$. Nevertheless, this electrostatic analysis provides an analytical evaluation of the Laplacian field distribution in the gap and demonstrates that the maximum field at the tip of the needle electrode is two orders of magnitude higher than the field in the middle of the gap.

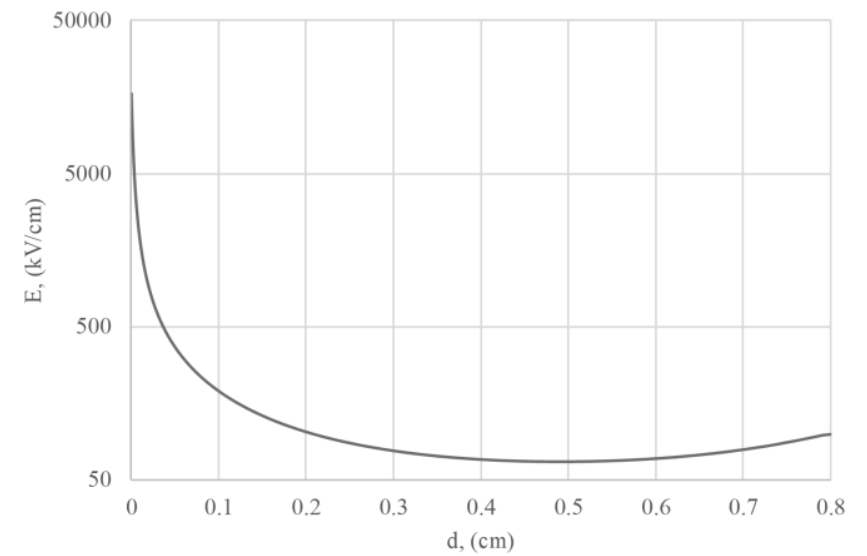

Fig.2. The magnitude of the electric field along the path between the tip of the HV needle $(0 \mathrm{~cm})$ and the pole of the grounded electrode $(0.8 \mathrm{~cm})$, the applied voltage is $150 \mathrm{kV}$.
The field distribution in the gap was obtained for different applied voltages using QuickField software, thus an equation linking $E_{\max }$ and $V_{b k}$ was established:

$$
E_{\max }(\mathrm{kV} / \mathrm{cm}) \approx 110.3 \cdot V_{b k}(\mathrm{kV})
$$

$E_{\max }$, given by Eq.(1), was compared with the maximum field values calculated using the analytical expression from [27], which is a strong function of the tip radius. It was found that the QuickField model provides $E_{\max }$ values $\sim 20 \%$ greater than the analytical expression, [27], for the same nominal radius of the tip of the needle electrode. Although the field magnitude at the tip of the practical needle electrodes used in the breakdown tests is known only approximately, the obtained $E_{\max }$ values can be used in the estimation of the field utilisation factor. In order to enable this analysis the "average" breakdown field, $E_{a v}$, which is used for characterisation of the field non-uniformity, should be calculated. $E_{a v}$ is obtained by dividing the breakdown voltage by the inter-electrode distance, [46]:

$$
E_{a v}=V_{b k} / d,
$$

where $d=0.8 \mathrm{~cm} . E_{a v}$ has the same order of magnitude as the field in the middle of the gap, obtained through modelling of the electrostatic field distribution. Thus, using Eqs. (1) and (2), the field utilisation factor for the present electrode topology can be obtained:

$\eta=E_{a v} / E_{\max } \approx 0.01$

\section{Test Procedure}

Extensive published research currently exists which defines the breakdown behaviour of ester dielectric liquids when exposed to lightning impulse voltages $(1.2 / 50 \mu \mathrm{s})$, [19-26], following the breakdown procedure(s) in the power industry standards. However, in the case of practical pulsed power systems and apparatuses, dielectric liquids are stressed with other wave-shapes. To increase understanding of the breakdown parameters exhibited by different insulating liquids in pulsed power regimes, this work moves away from the commonly used lighting voltage wave-shape and test procedures with the aim to obtain the breakdown behaviour of the ester fluids and the mineral oil in the overstressed regime. This regime facilitates each breakdown event on a rising slope of HV impulse thus provides a direct link between breakdown voltage and time delay to breakdown, $V_{b k}$ and $t_{b k}$.

Once the test cell had been filled with the liquid of interest the test cell was placed under vacuum for $30 \mathrm{~min}$ to remove possible gas bubbles before a sequence of breakdown tests were performed.

Eleven breakdown events were observed in each fresh sample; with the first breakdown logged creating a dataset of "first breakdown events" for each of the test liquids. Then, the breakdown voltage and time associated with the next 10 breakdown events were recorded. After the 11 registered breakdown events both the HV needle and ground spherical electrodes were replaced and a fresh liquid sample was 
introduced into the test cell. In total, 3 new samples of each liquid in each RH state were examined. This resulted in a dataset of 33 individual breakdown events for a given liquid and state of relative humidity. This was then separated into two discrete datasets; initial breakdown events $(\mathrm{n}=3)$ and those proceeding the initial event $(\mathrm{n}=30)$.

\section{Wave-form Treatment and Statistical Analysis}

The experimentally obtained voltage wave-forms contain distortions at the early stages of the HV impulse. Such distortions resulting from parasitic inductances and capacitive coupling may reduce the accuracy of measurement of the breakdown parameters. To mitigate this, it was assumed that the output waveform of the Marx generator prior to breakdown was independent of the liquid filling the test cell and could be described by the function:

$$
V(t)=V_{0}(1-\exp (-t / \tau))
$$

where $V_{0}$ and $\tau$ are fitting constants. It was found that all of the experimental waveforms could be fitted to this function with $V_{0}=140 \pm 2 \mathrm{kV}$ and $\tau=1.35 \cdot 10^{-6} \pm 3.2 \cdot 10^{-8} \mathrm{~s}$ with goodness of fit coefficients $\mathrm{R}^{2} \sim(0.98-1)$; achieved using Origin Pro graphing software. Examples of the experimental breakdown waveforms and corresponding fit lines obtained using (1), are shown in Fig. 3experimental breakdown wave-forms and corresponding fit lines obtained using Eq. (1), for are shown in Fig. 3.

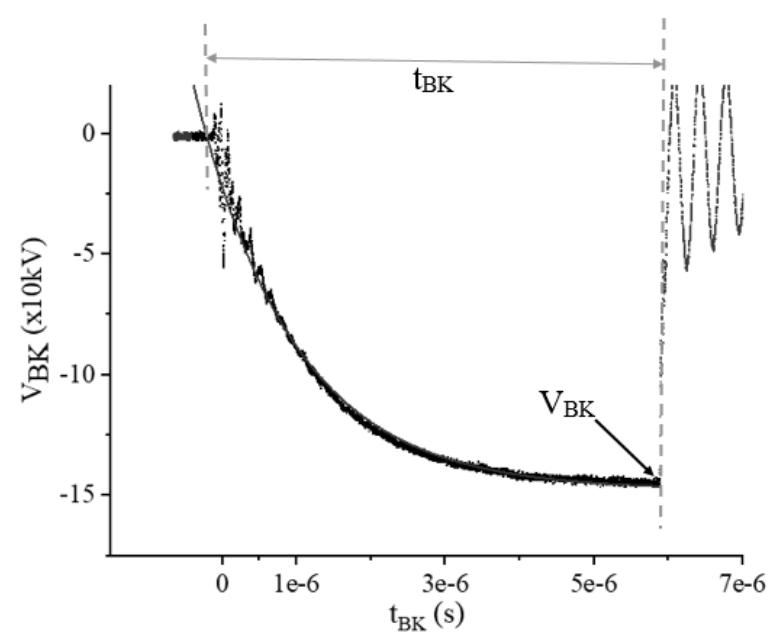

(a)

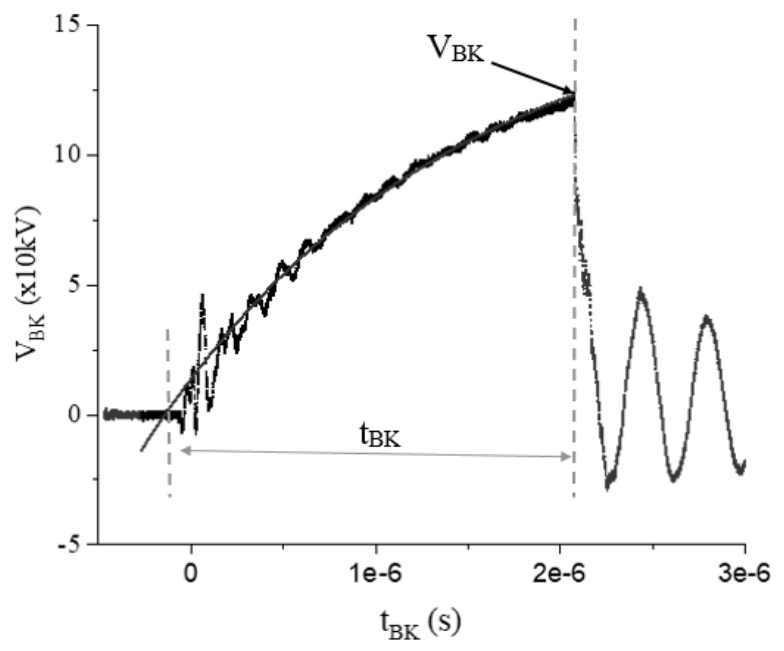

(b)

Fig. 3. Experimental negative (a) and positive (b) breakdown voltage waveforms; fitting lines obtained by Eq. (1).

Breakdown voltage $\left(V_{b k}\right)$ was obtained from the point on the fitted curve at which the collapse of the voltage signal occurs. The time to breakdown $\left(t_{b k}\right)$ was taken from the zero-crossing point of the exponential fit curve to the point when the signal is observed to collapse. To ensure comparability between all datasets obtained during experimentation the aforementioned fitting procedure was applied using identical exponential growth curve to all experimental waveforms to acquire the desired breakdown parameters $\left(V_{b k} \& t_{b k}\right)$.

\section{EXPERIMENTAL RESULTS}

\section{A. Positive HV impulses}

The breakdown voltage and time to breakdown, $V_{b k}$ and $t_{b k}$, obtained experimentally by stressing liquid samples with HV impulses of positive polarity, can be assumed to be normally distributed as all datasets subjected to the KolmogorovSmirnov (KS) normality test demonstrated $p$-values, ranging from 0.28 to $\sim 1$.

Figure 4 shows the cumulative probability function (CPF) plots of the breakdown voltage and time to breakdown in the case of natural ester Envirotemp FR3 liquid in "Ambient RH" state. The CPF for the normal distribution (grey lines) was fitted to the percentiles calculated using the experimental breakdown data (open circles). The fitting procedure was implemented using Origin Pro graphing software. The upper and lower 95\% confidence intervals are also shown. As all data sets were normally distributed, the mean values, standard deviations, percentiles and corresponding confidence intervals could be obtained. The values of the $5^{\text {th }}, 10^{\text {th }}, 50^{\text {th }}$ and $95^{\text {th }}$ percentiles of the breakdown voltage $\left(V_{5 \%}, V_{10 \%}, V_{50 \%}\right.$, and $\left.V_{95 \%}\right)$ and time to breakdown $\left(t_{5 \%}, t_{10 \%}, t_{50 \%}\right.$, and $\left.t_{95 \%}\right)$ are shown in Figure 4 . Figure 4(a) also shows the corresponding values of the average breakdown field, $E_{a v}$, obtained using Equation (2). 


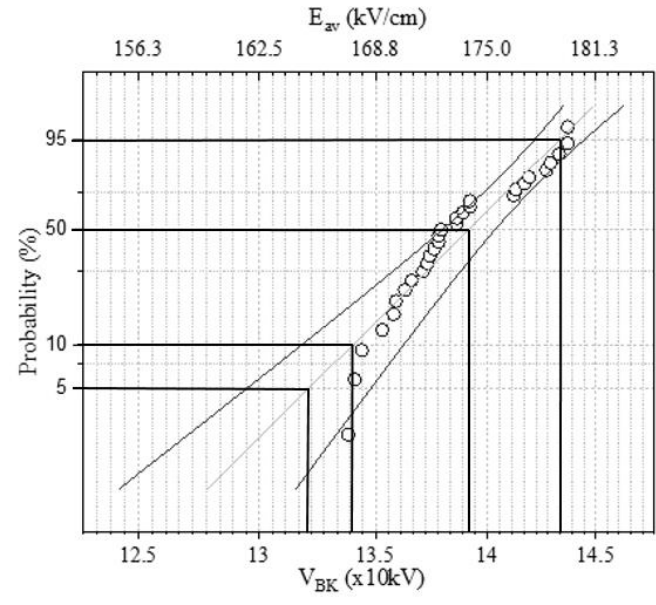

(a)

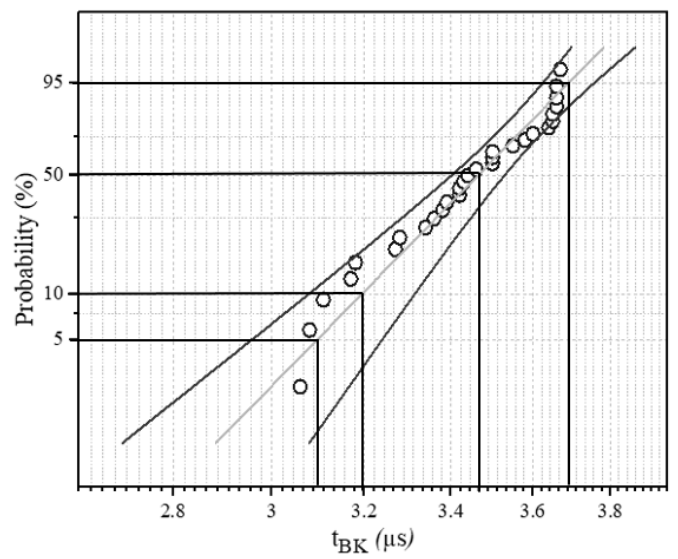

(b)

Fig. 4. Probability plots for Envirotemp FR3: CPF's for positive breakdown voltage, (a); and delay time to breakdown, (b). Experimental percentiles are shown as open circles, grey lines show reference CPF's, dark horizontal lines denote $5^{\text {th }}, 10^{\text {th }}, 50^{\text {th }}$ and $95^{\text {th }}$ percentiles and dark vertical lines corresponding values of $V_{5 \%}, V_{10 \%}, V_{50 \%}$, and $V_{95 \%}$, and $t_{5 \%}, t_{10 \%}, t_{50 \%}$, and $t_{95 \%}$.

It was shown that there is no statistically significant difference between the values of $V_{50 \%}$ and $t_{50 \%}$ obtained using the corresponding CPFs, and the mean values of $V_{b k}$ and $t_{b k}$ calculated by division of the sum of the measured values by the number of measurements, $\Sigma V_{b k} / n$ or $\Sigma t_{b k} / n$. Thus, mean values for the breakdown voltage and time to breakdown were used to characterise the breakdown behaviour of the insulating liquids.

Figure 5 shows the mean breakdown voltage, the average breakdown field, $E_{a v}$, obtained by Equation (2), and the mean time to breakdown for all tested liquids, for the case of $\mathrm{HV}$ impulses with positive polarity. Analysis of the results shown in Figure 5 demonstrate that breakdown voltages registered for Envirotemp FR3 are $\sim 1.7$ and $\sim 1.4$ times greater than that of the synthetic ester and mineral oil respectively.

If first breakdown events are not taken into account, the synthetic ester MIDEL 7131 exhibited the lowest positive breakdown voltages amongst the tested liquids. However, when only the initial breakdowns of the synthetic ester samples are considered, it is evident that, when in the low and medium states of relative humidity, $V_{b k}$ for MIDEL 7131 is statistically similar to that of mineral oil.

Figure 5a shows no statistically significant variation in breakdown voltage as relative moisture content is changed in all tested liquids (overlapping 95\% confidence error bars for all levels of relative humidity are observed in Figure 5a).

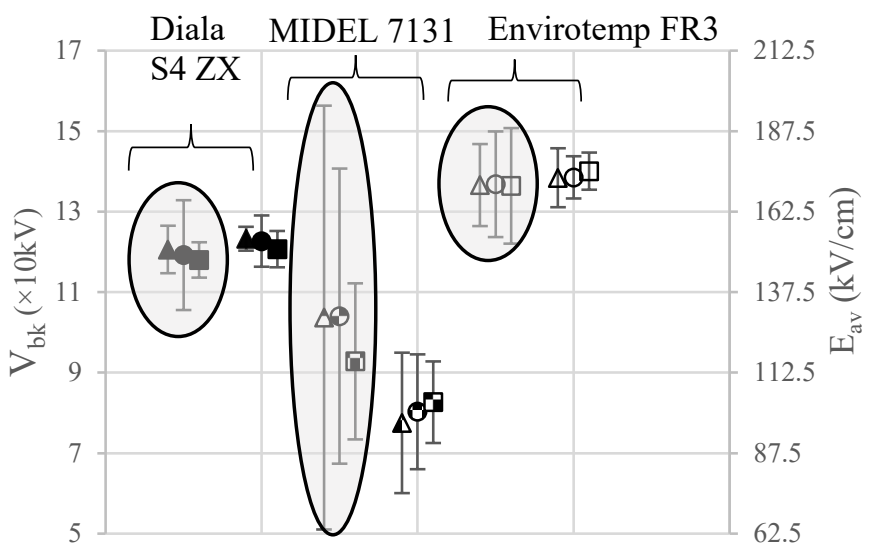

(a) Envirotemp FR3

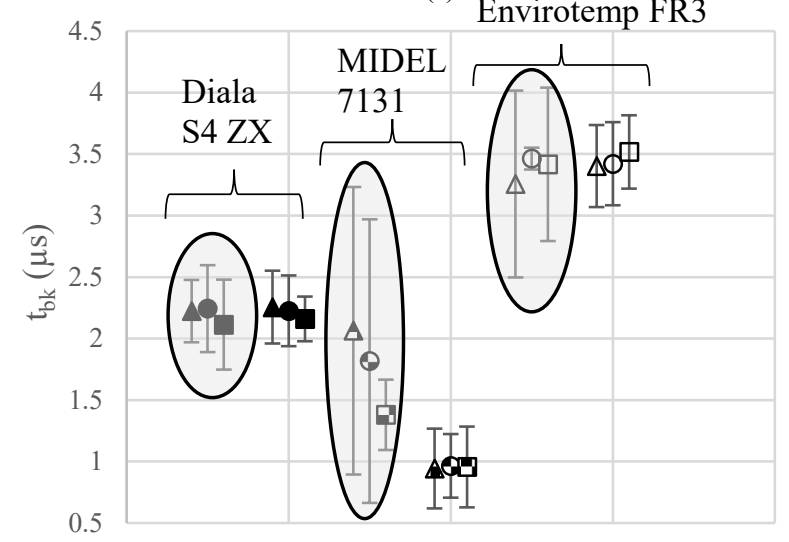

(b)

Fig. 5. Breakdown voltage and average breakdown field (a), and time to breakdown (b) for positive HV impulses. $\Delta$ : 'As Received' condition, ○: 'Ambient RH' and $\square$ : 'Elevated RH'. Open shapes, Envirotemp FR3; solid shapes, Shell Diala S4 ZX; patterned shapes, MIDEL 7131. Circled areas denote 'first breakdown'. Error bars represent $95 \%$ confidence intervals.

When examining $t_{b k}$ (Figure 5(b)), as all breakdown events occurred on the rising edge of the waveform, the trends observed are closely correlated with the breakdown voltage measurements.

In the case of Diala S4 ZX and Envirotemp FR3 dielectric liquids, there is no statistically significant difference in the time to breakdown obtained for first breakdown events in fresh liquid samples and further 10 breakdown events. However, the time to breakdown registered for first breakdown events in MIDEL 7131 ester liquid is longer that the time to breakdown obtained for the next 10 breakdown events in this dielectric liquid. Also, as with breakdown voltage, there exists no statistically significant variation in $t_{b k}$ for a given dielectric fluid as the relative moisture content of the fluid is increased.

The sensitivity of the AC breakdown voltage of minerals oils to their moisture content is well documented: a two-fold decrease in the AC breakdown voltage was reported in $[8,9]$ when the RH of the oil was increased from $<10 \% \mathrm{RH}$ to $30-40 \%$ RH. The AC breakdown voltages of the ester liquids, MIDEL 7131 and Envirotemp FR3, demonstrated an 
approximate two-fold decrease when their RH values were increased from $10 \%$ to $40-50 \%$, [5]. The rate of rise of the $\mathrm{AC}$ voltage in $[5,9]$ was $0.5 \mathrm{kV} / \mathrm{s}$, thus the pre-breakdown time was as long as tens of seconds.

In the present work, the time to breakdown was significantly shorter, less than $10 \mu \mathrm{s}$ in all cases. No statistically significant influence of the moisture content on the breakdown voltage and pre-breakdown time was obtained under such impulsive breakdown conditions. Further investigation is required to elucidate the exact mechanism(s) of breakdown in the case of long (tens of seconds) AC stress and short, $\mu$ s, impulsive stress; different processes such as global Joule heating and the resultant formation of gas cavities, and the propagation of fast ionisation fronts through the liquid bulk, could play various roles in these energisation regimes.

The obtained values of $V_{5 \%}, V_{10 \%}, V_{50 \%}$, and $V_{95 \%}$, and of $t_{5 \%}$, $t_{10 \%}, t_{50 \%}$, and $t_{95 \%}$ for all these liquids are shown in Figure 6 . These calculated values can be compared with the experimental breakdown voltage and time to breakdown values in the estimation of potential risks in insulation coordination based on statistical analysis. Figure 6(a) also shows the corresponding values of the average breakdown field obtained by Equation (2).

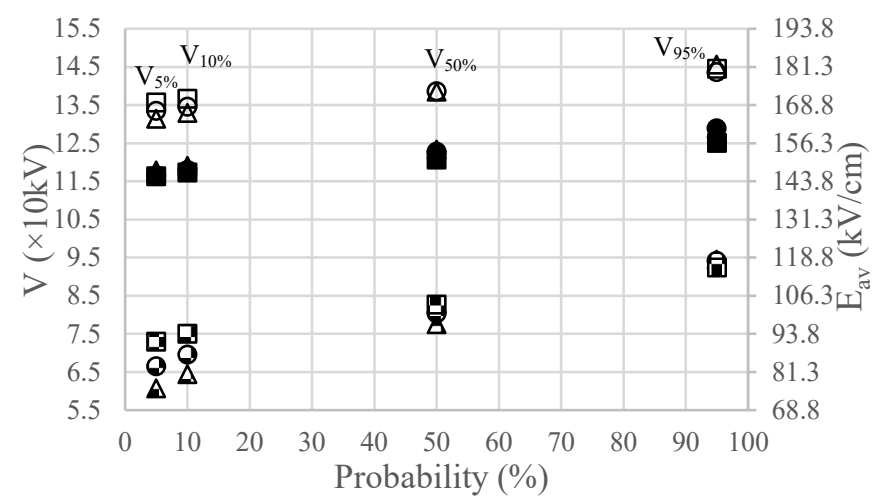

(a)

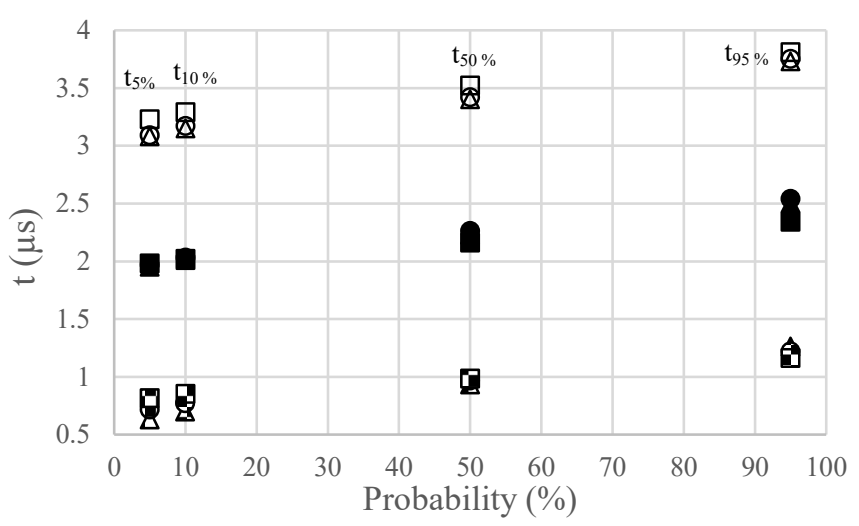

(b)

Fig. 6. $V_{5 \%}, V_{10 \%}, V_{50 \%}$, and $V_{95 \%}$ (a) and $t_{5 \%}, t_{10 \%}, t_{50 \%}$, and $t_{95 \%}$ (b) for positive energisation. $\Delta$ : 'As Received' condition, $\circ$ : 'Ambient RH' and $\square$ : 'Elevated RH'. Open shapes represent FR3, solid shapes detail Shell Diala S4 ZX and patterned MIDEL 7131. Values of $E_{a v}$ obtained by Equation (2) are given in (a).

\section{B. Negative HV impulses}

The breakdown voltage and time to breakdown datasets obtained for negative HV impulses were all normally distributed, based on the results of the KS normality test. Figure 7 shows the mean breakdown voltage, the average breakdown field, $E_{a v}$, obtained by Equation (2), and the mean time to breakdown for all tested liquids, in the case of $\mathrm{HV}$ impulses of negative polarity.

It was found that the synthetic ester MIDEL 7131 exhibits significantly higher values of $V_{b k}$ in all examined states of relative humidity; with recorded values, on average, $\sim 23 \%$ and $\sim 10 \%$ higher than that of the natural ester Envirotemp FR3 and mineral oil Shell Diala S4 ZX respectively. No statistically significant difference in negative breakdown voltages and time to breakdown was registered for first breakdown events and for following 10 breakdowns in all tested liquids.

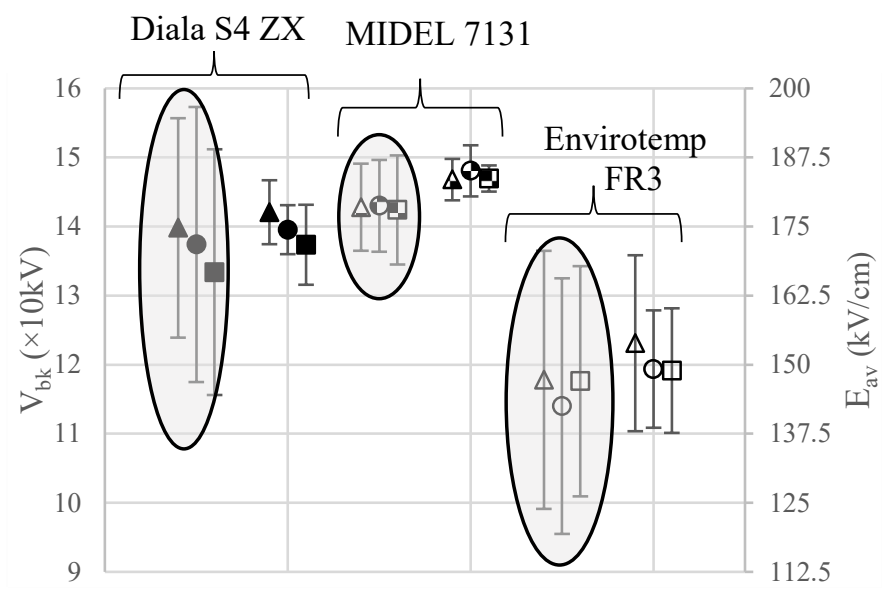

(a)

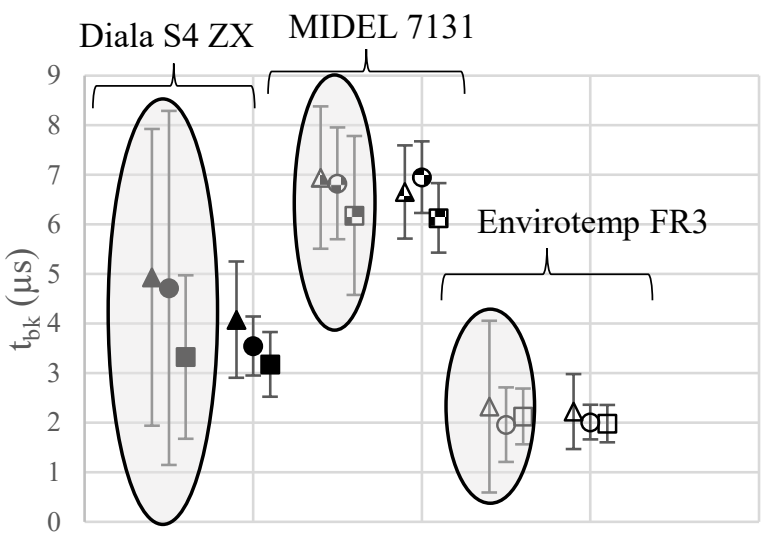

(b)

Fig. 7. Breakdown voltage (a) and time to breakdown (b) for negative HV impulses. $\Delta$ : 'As Received' condition, o: 'Ambient RH' and $\square$ : 'Elevated RH'. Open shapes, EnvirotempFR3; solid shapes, Shell Diala S4 ZX, patterned shapes MIDEL 7131. Circled areas denote 'first breakdowns'. Error bars represent $95 \%$ confidence intervals.

However, when measuring the breakdown voltage of the synthetic ester MIDEL 7131, the breakdown events consistently occurred when the voltage reached its maximum value, on the peak plateau of the voltage wave-form, or occasionally even on the initial phase of the falling edge of the 
impulse. Consequently, the breakdown voltage may show minimum variation for such breakdown events. In this case the time delay to breakdown can be a more indicative parameter then the breakdown voltage in the understanding of the breakdown performance of the dielectric fluid. It was shown that the synthetic ester MIDEL 7131 exhibits significantly longer times to breakdown, $t_{b k}$, as compared with other tested liquids used in this work: $\sim 210 \%$ and $\sim 93 \%$ longer than that of the natural ester FR3 and mineral oil Shell Diala S4 ZX respectively when in the highest state of relative humidity (Elevated RH).

The negative breakdown voltage and time to breakdown of Shell Diala S4 ZX liquid demonstrate an apparent decrease with increasing moisture content. However, as $95 \%$ confidence intervals for breakdown voltages and time to breakdown are overlapping, this reduction cannot be seen as being statistically significant.

The obtained values of the $5^{\text {th }}, 10^{\text {th }}, 50^{\text {th }}$ and $95^{\text {th }}$ percentiles of the negative breakdown voltage $\left(V_{5 \%}, V_{10 \%}, V_{50 \%}\right.$, and $\left.V_{95 \%}\right)$, and of the time to breakdown $\left(t_{5 \%}, t_{10 \%}, t_{50 \%}\right.$, and $\left.t_{95 \%}\right)$ obtained by fitting the normal distribution to the experimental data sets are shown in Figure 8. Figure 8(a) also shows the corresponding values of the average breakdown field obtained by Equation (2).

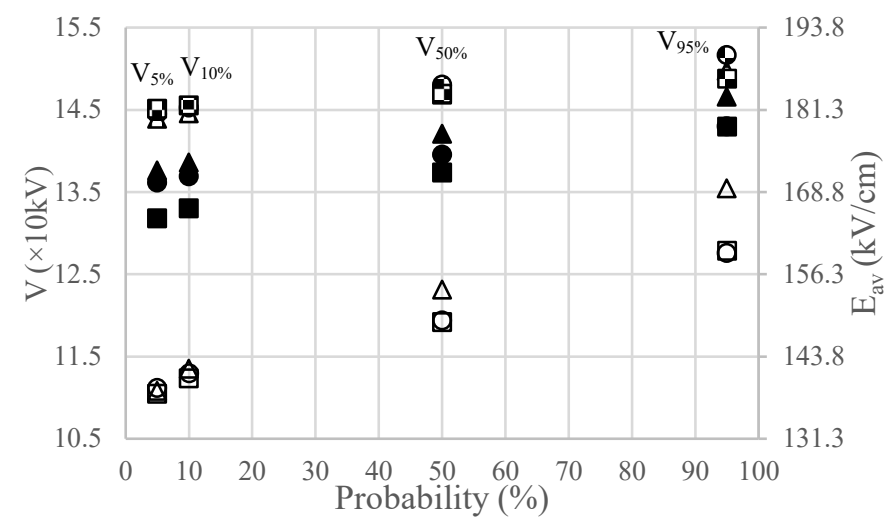

(a)

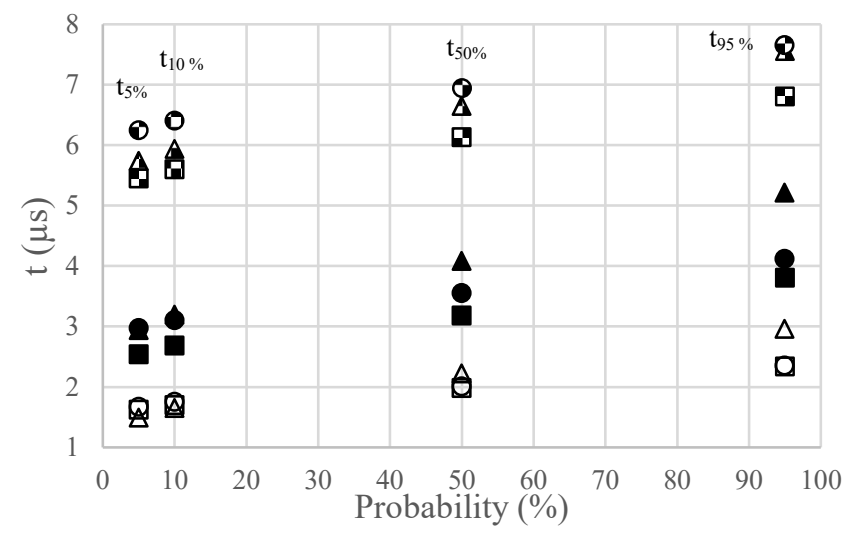

(b)

Fig. 8. $V_{5 \%}, V_{10 \%}, V_{50 \%}$, and $V_{95 \%}$ (a) and $t_{5 \%}, t_{10 \%}, t_{50 \%}$, and $t_{95 \%}$ (b) for negative energisation $\Delta$ : 'As Received' condition, $\circ$ : 'Ambient RH' and $\square$ : 'Elevated RH'. Open shapes represent FR3, solid shapes detail Shell Diala S4 ZX and patterned MIDEL 7131. Values of $E_{a v}$ obtained by Equation (2) are given in (a).
These values show behaviour similar to that of the mean values of the breakdown voltage and time to breakdown obtained for all tested liquids and presented in Figure 7.

\section{Discussion of Experimental Findings}

Statistical analysis of the obtained breakdown data demonstrates that no statically significant variation in breakdown voltage and time to breakdown for the dielectric fluids examined exists as relative moisture content is increased.

When evaluating how the polarity of the HV impulses affects the breakdown characteristics of the tested insulting liquids, it was established that a statistically significant sensitivity to the polarity of the applied HV impulses exists. The obtained results demonstrate that the ester liquids exhibit conflicting behaviour for a given polarity of the applied HV impulses.

When exposed to a positive HV tip the natural ester Envirotemp FR3 demonstrated the highest breakdown voltage and longest time to breakdown, above those for the mineral oil and the natural ester for all humidity levels, Figure 5. The synthetic ester MIDEL 7131 performed similarly to the mineral oil Shell Diala S4 ZX when only first breakdown events were taken into account, and worse when the further 10 breakdown events in each sample were considered.

Under negative energisation, inverse results to those of the positive energisation tests were observed under the present experimental conditions, for the natural ester Envirotemp FR3. This liquid demonstrated higher positive breakdown voltage and longer time to breakdown as compared with $V_{b k}$ and $t_{b k}$ obtained for negative impulses (for both cases, first breakdown events and 10 following breakdown events). The synthetic ester MIDEL 7131 demonstrated better dielectric performance under negative energisation than both the natural ester Envirotemp FR3 and mineral oil Shell Diala S4 ZX, Figure 7.

The dielectric behaviour of both the synthetic ester and mineral oil obtained in this work is typical of that described in literature; with positive breakdown voltage higher than negative breakdown voltage [19], [28-30]. This is not the case for the natural ester; with positive breakdown voltage for Envirotemp FR3 being, on average, up to $\sim 18 \%$ higher (Elevated RH) than when under negative impulse stress. [41] reports similar results to those observed within this experimental work under lightning impulses for the Envirotemp FR3 liquid with a higher impulse breakdown strength being observed for positive polarities. However, the electrode systems considered were designed to model transformer winding systems and included layers of paper insulation.

Breakdown behaviour where the positive breakdown voltage was greater than or equal to the negative breakdown voltage has been reported in literature, [31-36]. These behaviours are commonly observed in well-defined high purity liquids. In general, the liquids that exhibit this behaviour either contain halogen atoms or can attach electrons due to the presence of delocalised $\pi$ orbitals in their molecular structure. This allows the removal of energetic electrons from the system leading to the formation of negative ions with a low mobility as compared with electronic mobility, $[31,35,36]$. In [31] the authors suggest that the difference in the development of space charge in the gap when more mobile electrons are replaced by less mobile negative ions causes the breakdown strength under 
negative energisation to approach that under positive energisation.

Given that one of the advantages of ester fluids is their reduced environmental impact it is unlikely that any halogen atoms have been added to the molecular structure of the ester used in Envirotemp FR3. Therefore, additional information relating to the specific composition of the natural ester is required. In [42] a brief description is given for the formula used to manufacture Envirotemp FR3, however no clear details are given as to the specific additives used just an acknowledgement of their presence and concentration $(5 \% \mathrm{vol})$.

In the current work the stress applied to the gap is significantly different to the normally used lightning impulse with a considerably slower rise time of $7 \mu \mathrm{s}$. The possible differences in the development of space charge in the system with this higher value of rise time may be the cause of the anomalous behaviour of Envirotemp FR3 under positive HV impulses. Further research is being undertaken to examine the behaviour of breakdown under overstressed conditions with lower impulse rise times.

It is evident that there is a strong correlation between the time delay to breakdown and breakdown voltage for all investigated dielectric fluids when exposed to $\mathrm{HV}$ impulses of positive polarity; resulting from the breakdowns occurring on the rising edge of the wave-form due to the overstressing of the gap. When examining the time to breakdown recorded during negative polarity experimentation, as with the positive data, $V_{b k}$ and $t_{b k}$ have a strong correlation. However, the variation between the breakdown voltage of the synthetic ester and mineral oil is much lower than the differences in delay time; $\sim 7 \%$ and $\sim 95 \%$ respectively for the liquids when in the Elevated RH state. This is arising as the breakdown of the natural ester is occurring near the peak of the wave-form and in certain cases on the falling edge.

\section{CONCLUSION}

Based on analysis of the obtained experimental results it has been established that the investigated natural ester Envirotemp FR3 and synthetic ester MIDEL 7131 offer impulsive breakdown performance comparable to that of the mineral oil Shell Diala S4 ZX for the experimental conditions used. It was found that the natural ester outperforms both the synthetic ester and mineral oil under positive energisation but exhibited the lowest dielectric strength when exposed to negative voltage impulses. The mechanism behind this atypical behaviour cannot be explained at this point and additional research is being undertaken.

The water content of the investigated dielectric fluids has been shown to have no statistically significant influence over the breakdown behaviours in the experimental conditions used in the present paper. Further investigation is required to establish exact breakdown mechanism(s), which will help to explain the obtained dependencies: for example, the role of fast ionisation waves (streamers), Joule heating and formation of gas cavities, development of space charge and field redistribution should be studied and analysed.

From the experimental results obtained, and analysis undertaken, it is evident that the studied ester dielectric fluids offer comparable, at times superior, dielectric performance to the investigated naphthenic oil. However, further research is required in order to fully understand the phenomenon which determine the electrical breakdown dynamics of these nonconventional insulating liquids.

\section{REFERENCES}

[1] United Nations / Framework Convention on Climate Change (2015) Adoption of the Paris Agreement, 21st Conference of the Parties, Paris: United Nations, 2015.

[2] CIGRE Working Group A2.35, "New Experiences in Service with New Insulating Liquids", Brochure No: 436, ISBN: 978-2-85873-124-4, 2010.

[3] E. Gockenbach, H. Borsi, "Natural and Synthetic Ester Liquids as alternative to mineral oil for power transformers," 2008 Annual Report Conference on Electrical Insulation and Dielectric Phenomena, Quebec, QC, 2008, pp. 521-524.

[4] Siemens, "Alternative Transformer Fluids Energy Management Transformers", 2014. Available: https://assets.new.siemens.com/siemens/ assets/public.1502442783.8d1ea6691740ede03a1b3836f3fa3234a2c305dd.ipd f-alternative-fluids.pdf [Accessed on 20- Apr- 2020].

[5] I. Timoshkin, M. Given, M. Wilson, S. MacGregor, "Review of dielectric behaviour of insulating liquids", in International Universities Power Engineering Conference (UPEC), Glasgow, 2009. pp. 1-4

[6] K. Sindhuja, M. Srinivasan, N. Niveditha, "Natural Esters As An Alternative To Mineral Oil In Transformer Applications", International Journal of Pure and Applied Mathematics, vol. 118, no. 20, 2018.

[7] D. M. Mehta, P. Kundu, A. Chowdhury, V. K. Lakhiani and A. S. Jhala, “A Review on Critical Evaluation of Natural Ester vis-a-vis Mineral Oil Insulating Liquid for Use in Transformers: Part 1", IEEE Transactions on Dielectrics and Electrical Insulation, vol. 23, no. 2; pp.873-880, 2016.

[8] D. Martin, Z. Wang, "A Comparative Study of the Impact of Moisture on the Dielectric Capability of Esters for Large Power Transformers", in IEEE Conference on Electrical Insulation and Dielectric Phenomena, Kansas City, MO, USA, 2006, pp.409-412, DOI: 10.1109/CEIDP.2006.311956.

[9] "The Effect of Moisture on the Breakdown Voltage of Transformer Oil", White Paper of Vaisala, Available online: http://www.vaisala.com/Vaisala\%20Documents/White\%20Papers/CEN-TIApower-whitepaperMoisture-and-Breakdown-Voltage-B211282EN-ALOW.pdf (accessed on 20 April 2020).

[10] D. Martin, "Evaluation Of The Dielectric Capability Of Ester Based Oils For Power Transformers", PhD Thesis, University of Manchester, 2007.

[11] Y. Jing, I. Timoshkin, S. MacGregor, M. Given, M. Wilson, "Dielectric properties of natural ester, synthetic ester Midel 7131 and mineral oil Diala D", IEEE Transactions on Dielectrics and Electrical Insulation, vol. 21, no. 2, pp. 644-652, 2014.

[12] R. Frotscher, D. Vukovic, M. Jovalekic, S. Tenbohlen, "Behaviour of Ester Liquids under Dielectric and Thermal Stress - From Laboratory Testing to Practical Use", CIGRE Session 2012, D1-105, Paris 2012.

[13] M. Baur, J. Knauel, L. Calcara, M. Pompili, "Insultating Liquids Breakdown Voltage Determination: Test Method Efficiency," IEEE International Conference on Dielectric Liquids (ICDL), 2017, pp. 1-4.

[14] C. Perrier, A. Beroual, "Experimental investigations on insulating liquids for power transformers: mineral, ester, and silicone oils," IEEE Electrical Insulation Mag., vol. 25, pp. 6-136, 2009.

[15] F. Vahidi, S. Haegele, S. Tenbohlen, K. Rapp and A. Sbravati, "Study on moisture influence on electrical conductivity of natural ester fluid and mineral oil," 2017 IEEE Electrical Insulation Conference (EIC), Baltimore, MD, 2017, pp. $290-293$.

[16] S. Blume, M. Jaritz and J. Biela, "Design and Optimization Procedure for High-Voltage Pulse Power Transformers," in IEEE Transactions on Plasma Science, vol. 43, no. 10, pp. 3385-3391, Oct. 2015.

[17] IEC60897, "Methods for the determination of the lightning impulse breakdown voltage of insulating liquids," in International Electrotechnical Commission, 1987.

[18] Z.D. Wang, Q. Liu, X. Wang, P. Jarman, G. Wilson, "Discussion on possible additions to IEC 60897 and IEC 61294 for insulating liquid tests," IET Electr. Power Appl., vol. 5, no. 6, pp. 486-493, 2011.

[19] Q. Liu, Z. Wang, F. Perrot, "Impulse Breakdown Voltages of Ester-based Transformer Oils Determined by Using Different Test Methods", in IEEE Conference on Electrical Insulation and Dielectric Phenomena, Virginia Beach, VA, USA, 2009. 
[20] L. Rongsheng, A. Jaksts, "Breakdown processes in transformer insulation under LI voltages," in 2005 IEEE International Conference on Dielectric Liquids, 2005, pp. 75-78.

[21] F. M. J. McCluskey, A. Denat, and O. Lesaint, "Breakdown and prebreakdown phenomena in liquids under positive impulse voltages," Dielectrics and Electrical Insulation, IEEE Transactions on Electrical Insulation, vol. 1, pp. 377-382, 1994.

[22] Z. Wang, Q. Liu, X. Wang, P. Jarman and G. Wilson, "Discussion on possible additions to IEC 60897 and IEC 61294 for insulating liquid tests", IET Electric Power Applications, vol. 5, no. 6, p. 486, 2011.

[23] Q. Liu and Z. Wang, "Streamer characteristic and breakdown in synthetic and natural ester transformer liquids under standard lightning impulse voltage", IEEE Transactions on Dielectrics and Electrical Insulation, vol. 18, no. 1, pp. 285-294, 2011

[24] R. Liu, C. Tornkvist, V. Chandramouli, O. Girlanda and L. Petterson, "Ester fluids as alternative for mineral oil: The difference in streamer velocity and LI breakdown voltage", in IEEE Conference on Electrical Insulation and Dielectric Phenomena, Virginia Beach, VA, USA, 2009.

[25] P. Rozga, "Streamer propagation in a non-uniform electric field under lightning impulse in short gaps insulated with natural ester and mineral oil", Bulletin of the Polish Academy of Sciences Technical Sciences, vol. 64, no. 1, pp. 171-179, 2016.

[26] C. Duy, O. Lesaint, A. Denat and N. Bonifaci, "Streamer propagation and breakdown in natural ester at high voltage", IEEE Transactions on Dielectrics and Electrical Insulation, vol. 16, no. 6, pp. 1582-1594, 2009.

[27] R. Coelho, and J. Debeau, "Properties of the tip-plane configuration", J. Phys. D: Appl. Phys., vol. 4, pp. 1266-1280, 1970.

[28] S. Haegele, F. Vahidi, S. Tenbohlen, K. Rapp, A. Sbravati, "Lightning Impulse Withstand of Natural Ester Liquid", Energies, vol. 11, no. 8, p. 1964, 2018.

[29] M. Lashbrook, A. Gyore, R. Martin, "A review of the fundamental dielectric characteristics of ester-based dielectric liquids", Procedia Engineering, vol. 202, pp. 121-129, 2017.

[30] N. Nguyen, O. Lesaint, N. Bonifaci, A. Denat, M. Hassanzadeh, "A comparison of breakdown properties of natural and synthetic esters at high voltage", in Conference on Electrical Insulation and Dielectric Phenomena, West Lafayette, IN, USA, 2010.

[31] W. Schmidt, D. Pugh, "On the polarity effect of the breakdown voltage for dielectric liquids in an inhomogeneous field", Journal of Physics D: Applied Physics, vol. 10, no. 8, pp. 1139-1141, 1977.

[32] K. Yoshino, "Dependence of Dielectric Breakdown of Liquids on molecular Structure", IEEE Transactions on Electrical Insulation, vol. 15, no. 3, pp. 186-200, 1980.

[33] E. Forster, H. Yamashita, C. Mazzetti, M. Pompili, L. Caroli and S. Patrissi, "The effect of the electrode gap on breakdown in liquid dielectrics", IEEE Transactions on Dielectrics and Electrical Insulation, vol. 1, no. 3, pp. 440-446, 1994

[34] Y. Nitta and Y. Aihara, "Polarity Effect on Breakdown Voltage in Organic Liquids", IEEE Transactions on Electrical Insulation, vol. 11, no. 3, pp. 91-94, 1976.

[35] Y. Nakao, T. Yamazaki, K. Miyagi, Y. Sakai and H. Tagashira, "The effect of molecular structure on prebreakdown phenomena in dielectric liquids under a nonuniform field", Electrical Engineering in Japan, vol. 139, no. 1, pp. 1-8, 2002.

[36] E. Forster, C. Mazzetti, M. Pompili and R. Cecere, "The effect of molecular structure on the properties of dielectric fluids", IEEE Transactions on Electrical Insulation, vol. 26, no. 4, pp. 749-754, 1991.

[37] S. Tenbohlen and M. Koch, "Aging Performance and Moisture Solubility of Vegetable Oils for Power Transformers", IEEE Transactions on Power Delivery, vol. 25, no. 2, pp. 825-830, 2010.

[38] K. Miners, "Particles and Moisture Effect on Dielectric Strength of Transformer Oil Using VDE Electrodes", IEEE Power Engineering Review, vol. 2, no. 3, pp. 36-36, 1982.

[39] S. Haegele, S. Tenbohlen, K. Rapp and A. Sbravati, "Comparative study on inhomogeneous field breakdown in natural ester liquid and mineral oil", in IEEE Conference on Electrical Insulation and Dielectric Phenomena (CEIDP), Toronto, ON, Canada, 2016.

[40] J. Devins, S. Rzad, R. Schwabe, "Breakdown and prebreakdown phenomena in liquids", Journal of Applied Physics, vol. 52, no. 7, pp. 45314545, 1981.

[41] K. Rapp, J. Corkran, C. Mcshane, T. Prevost, "Lightning Impulse Testing of Natural Ester Fluid Gaps and Insulation Interfaces", IEEE Transactions on Dielectrics and Electrical Insulation, vol. 16, no. 6, pp. 1595-1603, 2009.
[42] "Cooper Envirotemp FR3 Product Selection and Description", 2005, Available: https:// ws680.nist.gov/bees/ProductListFiles/Cooper\%20 Envirotemp \%20FR3.pdf. [Accessed: 14- Jan- 2019].

[43] Shell Ltd, "Shell Diala S4 ZX-I Technical datasheet", 2014, Available: http://tdc.ge/wpcontent/uploads/2014/ 03/1_Diala_S4_ZX-I.pdf. [Accessed: 14- Jan- 2019].

[44] M\&I Materials Ltd, "MIDEL 7131 Synthetic Ester Transformer Fluid Fire safe and Biodegradable", 2019, Available: https://www.midel.com/app/uploads/2018/05/ MIDEL-7131-ProductBrochure.pdf. [Accessed: 16- Jan- 2019].

[45] Cargill Ltd, "Envirotemp FR3 Fluid Data Sheet", 2016, Available: https://www.cargill.com/doc/1432076501923/ envirotemp-fr3-r2000-tds.pdf. [Accessed: 08- Fed- 2019].

[46] M. Haerst, R. Bonin, C. Humpret, "Breakdown characteristics of liquid Nitrogen in strongly inhomogeneous Electric Fields", IEEE Transactions on Applied Superconductivity, v.26, n.3, pp. 7700305 1-5, 2016.

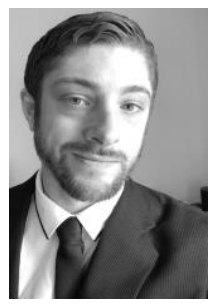

Chris Williamson (GS'19) received his B.Eng. (with honours) and subsequent M.Eng. degrees in electrical, electronic and energy engineering from Glasgow Caledonian University, Glasgow, U.K., in 2017 and 2018, respectively. He is currently based within the High Voltage Technologies research group at the University of Strathclyde, Glasgow, U.K. where he is pursuing a Ph.D. degree in electronic and electrical engineering. His research interests include impulse breakdown of liquid dielectrics focusing predominantly on environmentally friendly fluids, interfacial flashover of composite insulating systems and dielectric breakdown under non-standard voltage stress. Chris was a recipient of the IET award in 2017.

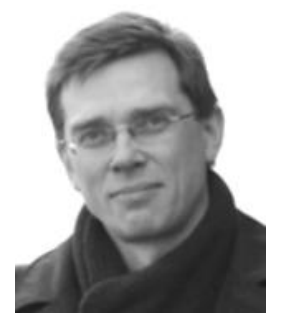

Igor V. Timoshkin (M'07-SM'14) received the degree in physics from Moscow State University, Moscow, Russia, in 1992, and the Ph.D. degree from the Imperial College of Science, Technology and Medicine (ICSTM), London, U.K., in 2001.

He was a Researcher at Moscow State Agro-Engineering University, Moscow, and then at the Institute for High Temperatures of Russian Academy of Sciences, Moscow. In 1997 he joined ICSTM. Then he joined the Department of Electronic and Electrical Engineering, University of Strathclyde, Glasgow, U.K., in 2001, where he became a Reader in 2016. His research interests include dielectric materials, pulsed power, transient spark discharges, environmental applications of non-thermal plasma discharges. Dr. Timoshkin is a Voting Member of the Pulsed Power Science and Technology Committee in the IEEE Nuclear and Plasma Science Society; a member of International Advisory Committee of the IEEE Conference on Dielectric Liquids, a member of the International Scientific Committee of the Gas Discharges and Their Application Conference, and a Subject Editor of IET Nanodielectrics. 


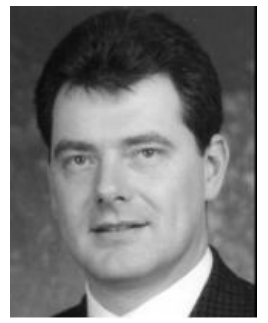

Scott J. MacGregor (M'95-SM'14) received the B.Sc. and Ph.D. degrees from the University of Strathclyde, Glasgow, U.K., in 1982 and 1986, respectively.

He was a Pulsed-Power Research Fellow in 1986 and a Lecturer in pulsed-power technology in 1989. In 1994, he became a Senior Lecturer, with a promotion to a Reader and a Professor of High Voltage Engineering, in 1999 and 2001, respectively. In 2006 and 2010, he became the Head of the Department of Electronic and Electrical Engineering and the Executive Dean of the Faculty of Engineering, and has been the Vice-Principal with the University of Strathclyde, since 2014. His current research interests include high-voltage pulse generation, high-frequency diagnostics, high-power repetitive switching, high-speed switching, electronic methods for food pasteurization and sterilization, the generation of high-power ultrasound (HPU), plasma channel drilling, pulsed-plasma cleaning of pipes, and the stimulation of oil wells with HPU. Prof. MacGregor was a recipient of the 2013 IEEE Peter Haas Award. He was an Associated Editor of the IEEE Transitions On Dielectrics and Electrical Insulation in 2015.

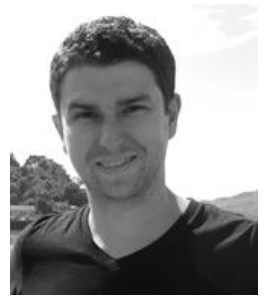

Mark P. Wilson (M'10) was born in Stranraer, Scotland, in 1982. He received the B.Eng. (with honours), M.Phil., and Ph.D. degrees in electronic and electrical engineering from the University of Strathclyde, Glasgow, U.K., in 2004, 2007, and 2011, respectively. $\mathrm{He}$ is presently based in the High Voltage Technologies research group at the University of Strathclyde, where his research interests include interfacial surface flashover, nanodielectrics, and the practical applications of high power ultrasound, corona discharges, and pulsed electric fields. Mark is a member of the IEEE Nuclear and Plasma Sciences Society, from whom he received a Graduate Scholarship Award in 2011, the IEEE Dielectrics and Electrical Insulation Society, and the IET.

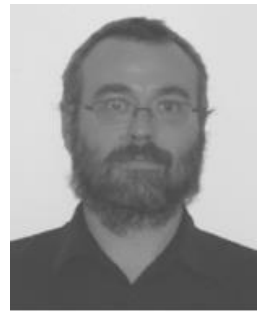

Martin J. Given (M'99-SM'11) received the B.Sc. degree in physics from the University of Sussex, Brighton, U.K., in 1981, and the Ph.D. degree in electronic and electrical engineering from the University of Strathclyde, Glasgow, U.K., in 1996.

He is currently a Senior Lecturer with the Department of Electronic and Electrical Engineering, University of Strathclyde. His current research interests include aging processes and condition monitoring in solid and liquid insulation systems, high-speed switching, and pulse power.

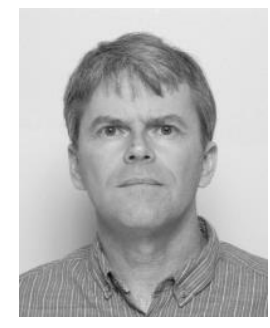

Mark Sinclair (M'03) received the B.Sc. degree from the Victoria University of Manchester, U.K., in 1990 and then went to St. Andrews and Strathclyde Universities in Scotland to receive an M.Sc. in Laser Engineering and Pulsed Power Technology. In 1992 he joined the Pulsed Power Group at AWE. Initially he worked on the E Minor machine moving on to Mogul E which was optimized for radiography of dense objects. In 2017 he was the Chair for the Pulsed Power Conference run in the UK for the first time.

Currently he is the technical lead for Pulsed Power capability at AWE running a number of programs to develop fundamental knowledge and skills, to develop new x-ray sources and to use Pulsed Power for Hydrodynamic simulation. He is a voting member of the NPSS Pulsed Power Science and Technology Committee.

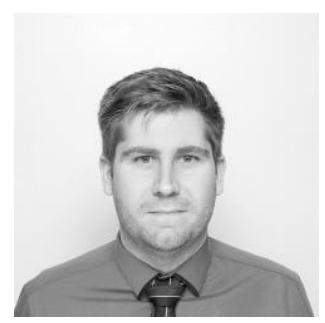

Aled Jones (M'10-SM'14) received the B.Sc.(Hons.) degree in physics from the University of Warwick, Coventry, U.K., in 2002.

Since then, he has worked for the Atomic Weapons Establishment (AWE), Aldermaston, U.K., in the field of pulsed power. At AWE, and on assignment at Sandia National Laboratories, Albuquerque, $\mathrm{NM}$, he has worked on developing flash radiographic sources. His research has involved Marx generators, pulse forming networks, inductive voltage addition, and electron beam diodes. In 2007, he was appointed Technical Authority for Pulsed Power in the Hydrodynamics department of AWE, and in 2010 he was also appointed Team Leader for Pulsed Power design. Since 2018 he has been a Senior Manager within the Physics sub-function at AWE with responsibility for development of high voltage accelerators. 